\title{
Chitosan oligosaccharide inhibits LPS-induced apoptosis of vascular endothelial cells through the BKCa channel and the p38 signaling pathway
}

\author{
JIAJIA LI ${ }^{1 *}$, JUNLIN HE ${ }^{2 *}$ and CHAO YU ${ }^{1}$ \\ ${ }^{1}$ Institute of Life Sciences and ${ }^{2}$ Laboratory of Reproductive Biology, School of Public Health, \\ Chongqing Medical University, Chongqing 400016, P.R. China \\ Received January 9, 2012; Accepted February 14, 2012
}

DOI: $10.3892 / \mathrm{ijmm} .2012 .954$

\begin{abstract}
Lipopolysaccharide (LPS) can cause injuries to the vascular endothelium and induce cell apoptosis resulting in various vascular diseases. However, the relevant processes and molecular mechanisms have not yet been fully clarified. Chitosan oligosaccharide (COS) can protect cells, but there are only a few reports showing that it can effectively inhibit LPS-induced cell apoptosis. This study focuses on human umbilical vein endothelial cells (HUVECs). After cells were treated with LPS for 4-8 h, it was found by flow cytometry that the cell apoptosis ratio, and the reactive oxygen species and calcium concentration in the cells increased. Furthermore, using the patch clamp technique, it was observed that the large conductance calcium-activated potassium channel (BKCa) was activated at the same time. All phenomena could be reversed after pretreatment with COS for $24 \mathrm{~h}$, showing that COS is capable of inhibiting LPS-induced cell apoptosis. The results of the assays on the action mechanism of COS show that it is capable of inhibiting the LPS-induced decrease of the Bcl-2/ Bax ratio, increase of caspase- 3 and activation of BKCa. Thus, one of the mechanisms of action of COS in the inhibition of cell apoptosis is to participate in the regulation of the $\mathrm{BKCa}$ channel. On the other hand, COS can inhibit the phosphorylation of LPS-induced p38 and accelerate the expression of O-GlcNAc glycosyltransferase, which indicates that COS can inhibit LPS-induced cell apoptosis through many pathways.
\end{abstract}

Correspondence to: Dr Chao Yu, Institute of Life Sciences, Chongqing Medical University, Box 174, 1 Yi Xue Yuan Road, Chongqing 400016, P.R. China

E-mail: yuchaom@163.com

${ }^{*}$ Contributed equally

Abbreviations: HUVECs, human umbilical vein endothelial cells; COS, chitosan oligosaccharide; LPS, lipopolysaccharide; Bcl-2, B cell lymphoma/leukemia-2; Bax, Bcl-2 associated X protein; p38/MAPK, p38 mitogen-activated protein kinase; OGT, O-GLcNAc transferase

Key words: chitosan oligosaccharide, patch clamp

\section{Introduction}

One of the initiating steps of atherosclerosis is the injury of vascular endothelial function which may be closely related to high blood pressure, diabetic vascular complications and cardio-cerebrovascular diseases (1). As a key component of gram-negative bacteria cell walls, lipopolysaccharide (LPS) may cause vascular endothelial cell (VEC) dysfunctions and release a series of inflammatory cytokines, thus accelerating the inflammatory injury process $(2,3)$. With respect to this kind of cell dysfunction model, research on an appropriate drug treatment that may prevent dysfunction and improve the cell function, so as to prevent atherosclerosis is needed.

Chitosan oligosaccharide (COS) is a natural alkaline polysaccharose, an oligosaccharide formed by 2-10 aminoglucoses through 1,4-glucosidic bond connection. With p38/ MAPK glycosylation modification, it was shown to inhibit the expression of IL- 6 and IL- 8 induced by TNF- $\alpha$ to EA.hy926 cells (4), and even to decrease the apoptosis ratio of primary cultured cortical neurons exposed to glucose deprivation (GD) by regulating related factors of apoptosis, such as Bcl-2. (5). In addition, $\mathrm{COS}$ has been reported to exert antitumor activity in A549 cells (6). However, whether COS could prevent the dysfunction of VEC is unknown. Moreover, there are seldom studies or reports on the mechanism of action of COS.

It has been reported that $\mathrm{H}_{2} \mathrm{O}_{2}$ can induce human umbilical vein endothelial cells (HUVECs) to release reactive oxygen species (ROS) and thus increases the calcium concentration in the cytoplasm $(7,8)$, which could be reversed by COS at the same time. However, the mechanism by which COS prevents cell dysfunction is not known. Thus, the focus of this study was to evaluate this mechanism and examine whether the effects of COS are related to the functions of ion channels on cell membranes. Some studies have found that there is some association between the opening of the BKCa channel of vascular smooth muscle cells (VSMCs) and streptozocin-induced diabetes (9). The opening of the BKCa channel can influence the activity of VEC, while this change may correlate with the occurrence of hypoxidosis. Salvianolic acid B could prevent the potassium chloride-induced opening of the BKCa channel (10). The opening of the BKCa channel can induce the phosphorylation of the AMPK signaling pathway (11). NO-induced 
apoptosis of pulmonary artery smooth muscle cells correlates with the opening of the BKCa channel (12). Taken together all the data suggest that the LPS-induced calcium concentration alteration within the cells may correlate with the status of the BKCa channel on the cell membrane. Whether COS can prevent LPS-induced vascular endothelial injury through this process is the main focus of this study.

\section{Materials and methods}

Materials. COS and HUVECs were obtained by the Dalian Institute of Chemical Physics, the Chinese Academy of Sciences; DMEM/F12 culture medium and fetal bovine serum (FBS) were purchased from Gibco (USA); while lipopolysaccharide, iberiotoxin and VitC were from Sigma; the RNA extraction reagent (TRIzol), RNA reverse transcription reagent and the PCR expansion reagent kit were from Takara Biotechnology (Dalian) Co., Ltd.; protein lysis buffer, anti- $\beta$-actin, anti-Bcl-2, anti-Bax, anti-caspase-3 antibodies were from Cell Signaling Technology; anti-O-GLcNAc transferase (OGT), anti-t-p38 MAPK, anti-phospho-p38 (p-p38) and other antibodies were from Santa Cruz Biotechnology, Inc.

Cell culture and drug treatment. HUVECs were cultured in DMEM/F12 medium supplemented with $10 \%$ inactivated FBS, $100 \mathrm{U} / \mathrm{ml}$ penicillin and $100 \mathrm{mg} / 1$ streptomycin at $37^{\circ} \mathrm{C}$ in a $5 \% \mathrm{CO}_{2}$ atmosphere. Pancreatin of $0.25 \%$ was digested for passage. When the cells grew into the logarithmic phase, some cells were taken out to inoculate in a culture plate or a culture flask for $12 \mathrm{~h}$, and added with COS medium of different concentrations (50 or $200 \mathrm{mg} / \mathrm{l}$ ) for 24-h pretreatment, while the blank control group was only added with the culture solution of the same volume and the positive control group was pretreated with VitC $(100 \mathrm{mg} / \mathrm{l})$ for the same hours. A corresponding cytological detection was conducted after treatment with LPS $(500 \mu \mathrm{g} / \mathrm{l})$ for $4-8 \mathrm{~h}$.

Bcl-2 and Bax mRNA expression detection by RT-PCR. After treatment with the above methods, the cells were stimulated by LPS for $4 \mathrm{~h}$ in order to extract the total cell RNA with the TRIzol reagent method and then reverse transcribed into cDNA for $15 \mathrm{~min}$ at $37^{\circ} \mathrm{C}$ then for $5 \mathrm{sec}$ at $85^{\circ} \mathrm{C}$. The Bcl-2 and Bax gene were amplified by the PCR technique using cDNA as a template. Specifically, the upstream and downstream Bcl-2 primers were, respectively, 5'-GAA GGA ATG TTG CAT GAG TCG GAT C-3' and 5'-AAG GGA ACT GCG GAT GTA AAG ATC C-3' with a product of $200 \mathrm{bp}$; the upstream and downstream Bax primers were 5'-TTT TGC TTC AGG GTT TCA TC-3' and 5'-GTT CTT CGA CTC GCT CAC AG-3' separately with a product of 146 bp; those of GAPDH were 5'-GTG GAA TCA TAT TGG AAC ATG T-3' and 5'-CTC TCT GCT CCT CCT GTT CGA CAG-3' with a product of $230 \mathrm{bp}$. After predenaturing at $94^{\circ} \mathrm{C}$ for $4 \mathrm{~min}, \mathrm{Bcl}-2$ was denatured at $94^{\circ} \mathrm{C}$ for $1 \mathrm{~min}$, annealed at $53^{\circ} \mathrm{C}$ for $45 \mathrm{sec}$, extended at $72^{\circ} \mathrm{C}$ for $50 \mathrm{sec}$ and amplified for 35 cycles; Bax was denatured at $94^{\circ} \mathrm{C}$ for $1 \mathrm{~min}$, annealed at $52^{\circ} \mathrm{C}$ for $45 \mathrm{sec}$, extended at $72^{\circ} \mathrm{C}$ for $1 \mathrm{~min}$ and amplified for 30 cycles. The PCR product was electrophoresed on a $1.5 \%$ agarose gel; a gel imager (Gel Doc 2000, Bio-Rad, USA) was used to analyze the results; GAPDH was used as an internal reference to evaluate the expression of IL-6 and IL-8.
Western blot analysis. The above-treated cells were lysed by CST lysis buffer (including 10\% Ser/Thr inhibitor, 10\% Tyr inhibitor and 10\% PMSF) then centrifuged at $12,000 \mathrm{x} \mathrm{g}$ for $15 \mathrm{~min}$ at $4^{\circ} \mathrm{C}$. The supernatant was collected and $5 \mathrm{X}$ protein loading buffer was added followed by boiling for $10 \mathrm{~min}$. After SDS-PAGE, the cells were transferred to a PVDF membrane. Membranes were blocked with 5\% nonfat dry milk for $1 \mathrm{~h}$, and incubated overnight with primary antibody (t-p38, p-p38, OGT, Bax, $\beta$-actin) at $4^{\circ} \mathrm{C}$, washed with TBST for 3 times, and then incubated with the corresponding horseradish peroxidase (HRP)-conjugated secondary antibody for $1 \mathrm{~h}$ at ambient temperature. The ECL chemiluminescence method was used to visualize the protein bands and the results were analyzed by the ChemDoc imager (Bio-Rad).

Cell apoptosis detection by flow cytometry. A certain number of cells were collected, followed by addition of $5 \mu \mathrm{l}$ FITC-labeled Annexin V and $2 \mu \mathrm{l} \mathrm{PI}$. They were well-mixed and bathed in warm water for $15 \mathrm{~min}$ at $37^{\circ} \mathrm{C}$ without light, followed by addition of $400 \mu \mathrm{l}$ buffer solution to detect cell apoptosis.

Intracellular ROS and $\mathrm{Ca}^{2+}$ detection by flow cytometry. When detecting intracellular ROS, the cell culture medium was washed away by PBS, followed by addition of the DCFH-DA fluorescent probe diluted with serum-free culture medium $(1: 5,000)$. After culturing for $1 \mathrm{~h}$, the cells were collected and the intracellular ROS detection was performed by flow cytometry.

When detecting the intracellular $\mathrm{Ca}^{2+}$ by flow cytometry, cells were treated in the same way and cultured for $30 \mathrm{~min}$ after addition of the Fluo-3-AM probe.

BKCa opening detection by patch clamp technique. The suspensions of the collected cells were evenly dripped on the prepared slide and left to stand for $5 \mathrm{~min}$. When sunk to the bottom and stuck to the wall, the slide was placed on the patch clamp for cell adhesion; the pClamp 6.01 procedure was used to collect and analyze the data in the whole-cell recording mode.

Statistical analysis. Each batch of experiments was repeated for at least 3 times and each group was required to have at least 3 replicates. The data are expressed as means \pm standard deviation, which was analyzed by the SPSS 11.0 software. The difference between the two groups was analyzed by the Student's t-test. Differences in the data between two or more groups were analyzed by the variance method. $\mathrm{P}<0.05$ indicates that the differences were statistically significant.

\section{Results}

COS inhibits LPS-induced cell apoptosis. In order to verify whether COS has a protective effect on LPS-induced endothelial cell injury, flow cytometry was used to detect cell apoptosis. The results show that the apoptosis ratio of HUVECs in the blank control group was $9.72 \%$, and it increased to $19.96 \%(\mathrm{P}<0.05)$ after being induced by LPS $(500 \mu \mathrm{g} / \mathrm{l})$ for $4 \mathrm{~h}$. After the cells were pretreated with COS (50 or $200 \mathrm{mg} / \mathrm{l}$ ) for $24 \mathrm{~h}$ and induced by LPS for $4 \mathrm{~h}$, the cell apoptosis ratios were 16.14 and $16.9 \%$, respectively. When cells were pretreated with the positive 

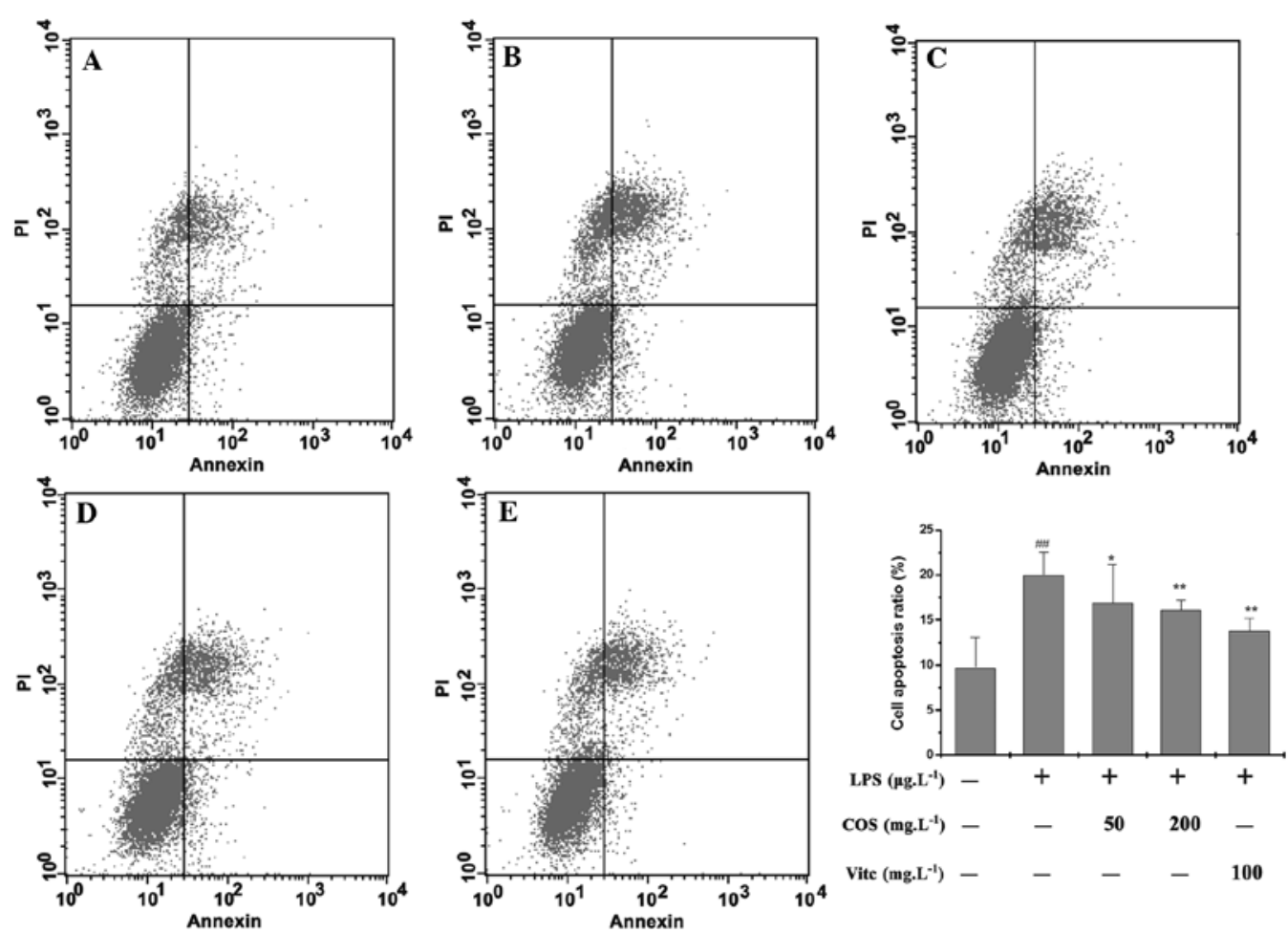

Figure 1. Effects of COS on LPS-induced injury cells. (A) Control group, (B) LPS-treated group, (C) COS (50 mg/l) + LPS (500 $\mu \mathrm{g} / \mathrm{l})$, (D) COS (200 mg/l) + LPS $(500 \mu \mathrm{g} / \mathrm{l}),(\mathrm{E}) \mathrm{VitC}(100 \mathrm{mg} / \mathrm{l})+\mathrm{LPS}(500 \mu \mathrm{g} / \mathrm{l}) .{ }^{\# \#} \mathrm{P}<0.01 \mathrm{vs}$. the vehicle-treated group; ${ }^{\mathrm{P}}<0.05$ vs. the LPS-treated group; ${ }^{* *} \mathrm{P}<0.01 \mathrm{vs}$. the LPS-treated group.
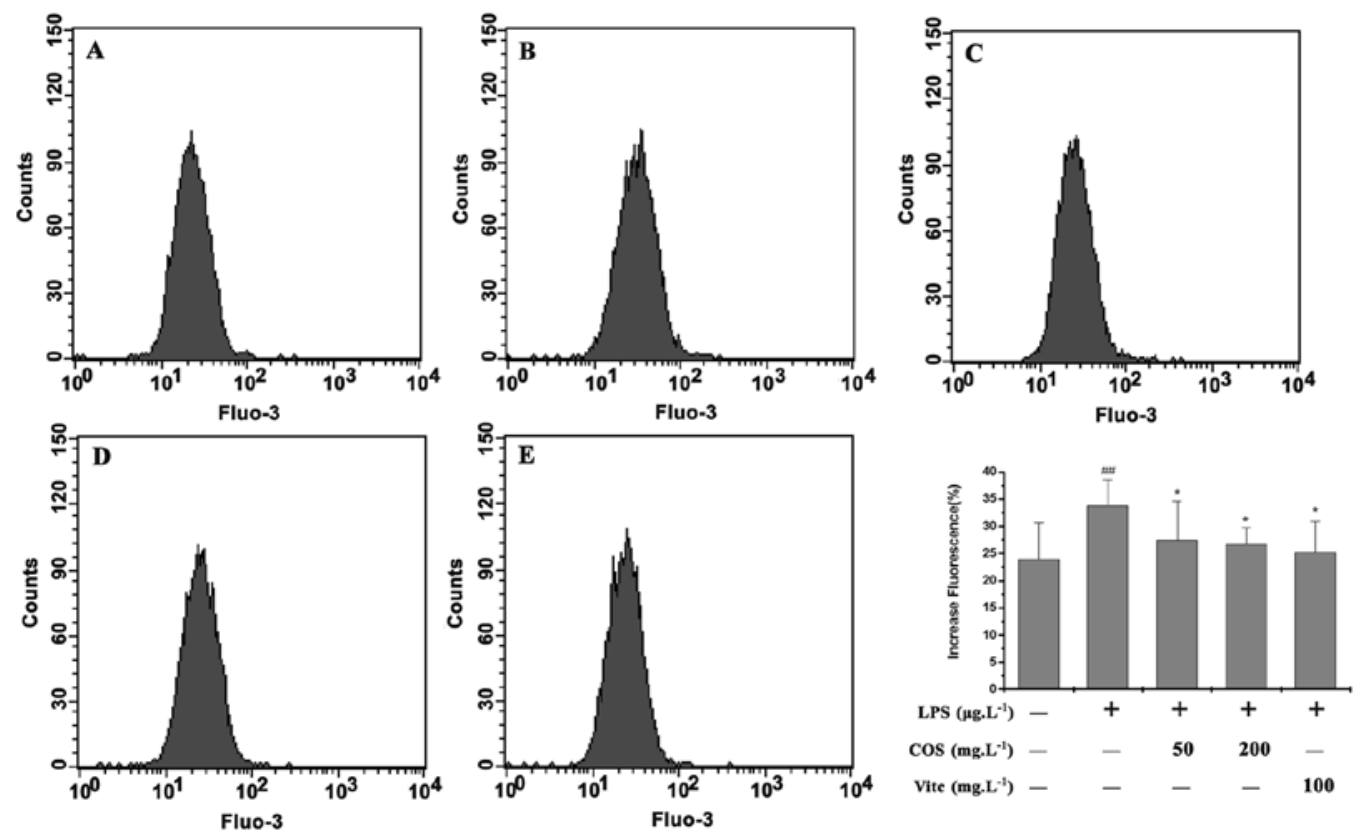

Figure 2. The LPS-induced fluorescence of intracellular $\mathrm{Ca}^{2+}$ was decreased after pretreatment by COS. (A) Control group, (B) LPS-treated group, (C) COS $(50 \mathrm{mg} / \mathrm{l})+\mathrm{LPS}(500 \mu \mathrm{g} / \mathrm{l}),(\mathrm{D}) \operatorname{COS}(200 \mathrm{mg} / \mathrm{l})+\mathrm{LPS}(500 \mu \mathrm{g} / \mathrm{l})$, (E) VitC $(100 \mathrm{mg} / \mathrm{l})+\mathrm{LPS}(500 \mu \mathrm{g} / \mathrm{l}) .{ }^{\# \#} \mathrm{P}<0.01 \mathrm{vs}$. the vehicle-treated group; ${ }^{* *} \mathrm{P}<0.05 \mathrm{vs}$. the LPS-treated group.

control, VitC $(100 \mathrm{mg} / \mathrm{l})$, and induced by LPS, the cell apoptosis ratio was $13.81 \%(\mathrm{P}<0.05)$ (Fig. 1). The results demonstrate that COS is capable of inhibiting the cell apoptosis induced by LPS.

COS inhibits the LPS-induced increase in intracellular $\mathrm{Ca}^{2+}$ and ROS concentration. Previous studies have indicated that cell apoptosis is closely related to $\mathrm{Ca}^{2+}$ overload and intracel- lular ROS increase. In order to verify whether COS could affect the $\mathrm{Ca}^{2+}$ and ROS concentration induced by LPS, flow cytometry was used to detect $\mathrm{Ca}^{2+}$ and ROS with Fluo-3-AM and DCFH-DA as probes, respectively. The results of $\mathrm{Ca}^{2+}$ detection demonstrate that the fluorescence intensity increased by 1.4-fold compared with the control group $(\mathrm{P}<0.05)$ (Fig. 2) after treatment with LPS. Compared with the LPS-induced 

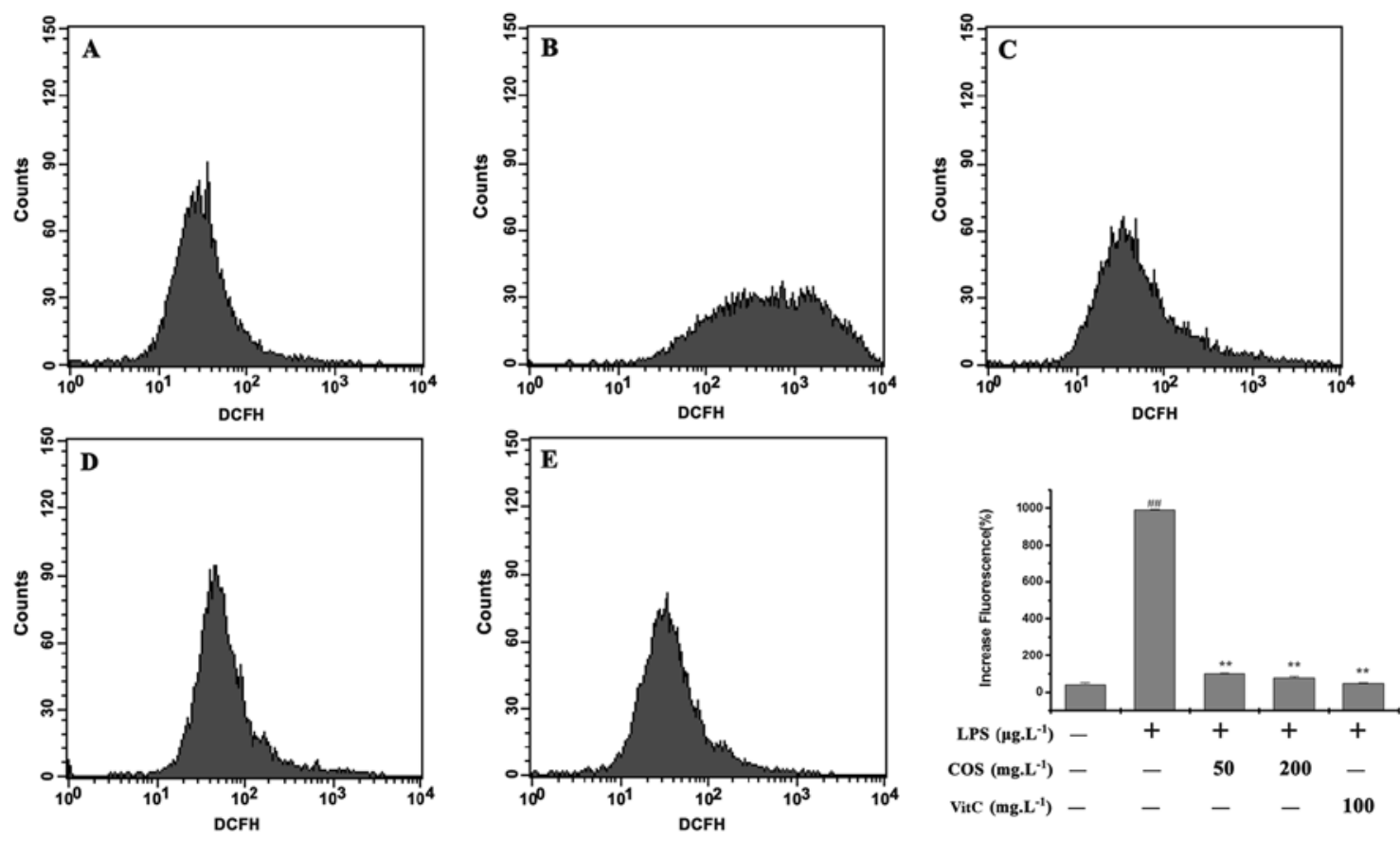

Figure 3. LPS-induced fluorescence of intracellular ROS was decreased after pretreatment with COS. (A) Control group, (B) LPS-treated group, (C) COS $(50 \mathrm{mg} / \mathrm{l})+$ LPS $(500 \mu \mathrm{g} / \mathrm{l}),(\mathrm{D}) \operatorname{COS}(200 \mathrm{mg} / \mathrm{l})+\mathrm{LPS}(500 \mu \mathrm{g} / \mathrm{l}),(\mathrm{E}) \mathrm{VitC}(100 \mathrm{mg} / \mathrm{l})+\mathrm{LPS}(500 \mu \mathrm{g} / \mathrm{l}) .{ }^{* \prime \prime} \mathrm{P}<0.01 \mathrm{vs}$. the vehicle-treated group; ${ }^{* *} \mathrm{P}<0.01 \mathrm{vs}$. the LPS-treated group.
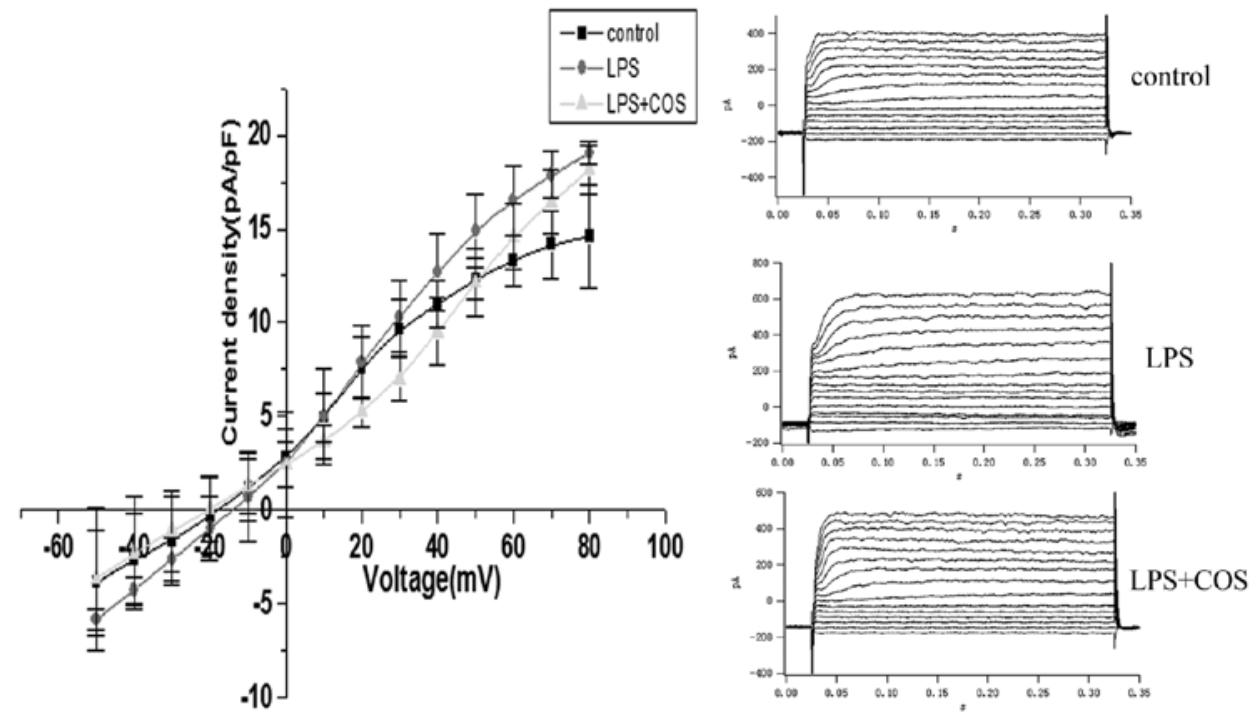

Figure 4. Effects of COS on BKCa channel of HUVEC induced by LPS.

cells, the fluorescence intensity markedly dropped after pretreatment with $\operatorname{COS}(50$ or $200 \mathrm{mg} / \mathrm{l})$ and with the positive control VitC (100 mg/l). The decreases were 1.15-, 1.11- and 1.05 -fold that of the control group, respectively. It can be seen that COS can effectively protect cells and maintain the balance of intracellular $\mathrm{Ca}^{2+}$ concentration.

Detection of intracellular ROS showed that the fluorescence intensity, compared with the control group, increased by 23.3 -fold $(\mathrm{P}<0.05)$ after treatment by LPS. However, compared with the LPS-induced cells, the fluorescence intensity was obviously decreased after pretreatment with COS (50 or $200 \mathrm{mg} / \mathrm{l}$ ) or treatment with the positive control group, VitC
(100 mg/l) (Fig. 3). The results show that COS can inhibit the increase of intracellular ROS concentration induced by LPS.

COS inhibits LPS-induced cell apoptosis through regulating the BKCa channel. COS has a noticeable effect on maintaining the balance of intracellular $\mathrm{Ca}^{2+}$ concentration. In order to verify whether this phenomenon is involved in the functions of the BKCa channel on the cell membranes, the patch clamp technique was applied. The results show that the BKCa channel, compared with the control group, was opened at a high voltage $(50-70 \mathrm{mV})$ after HUVECs were induced by LPS for $4 \mathrm{~h}(\mathrm{P}<0.05)$ (Fig. 4). However, in cells pretreated 

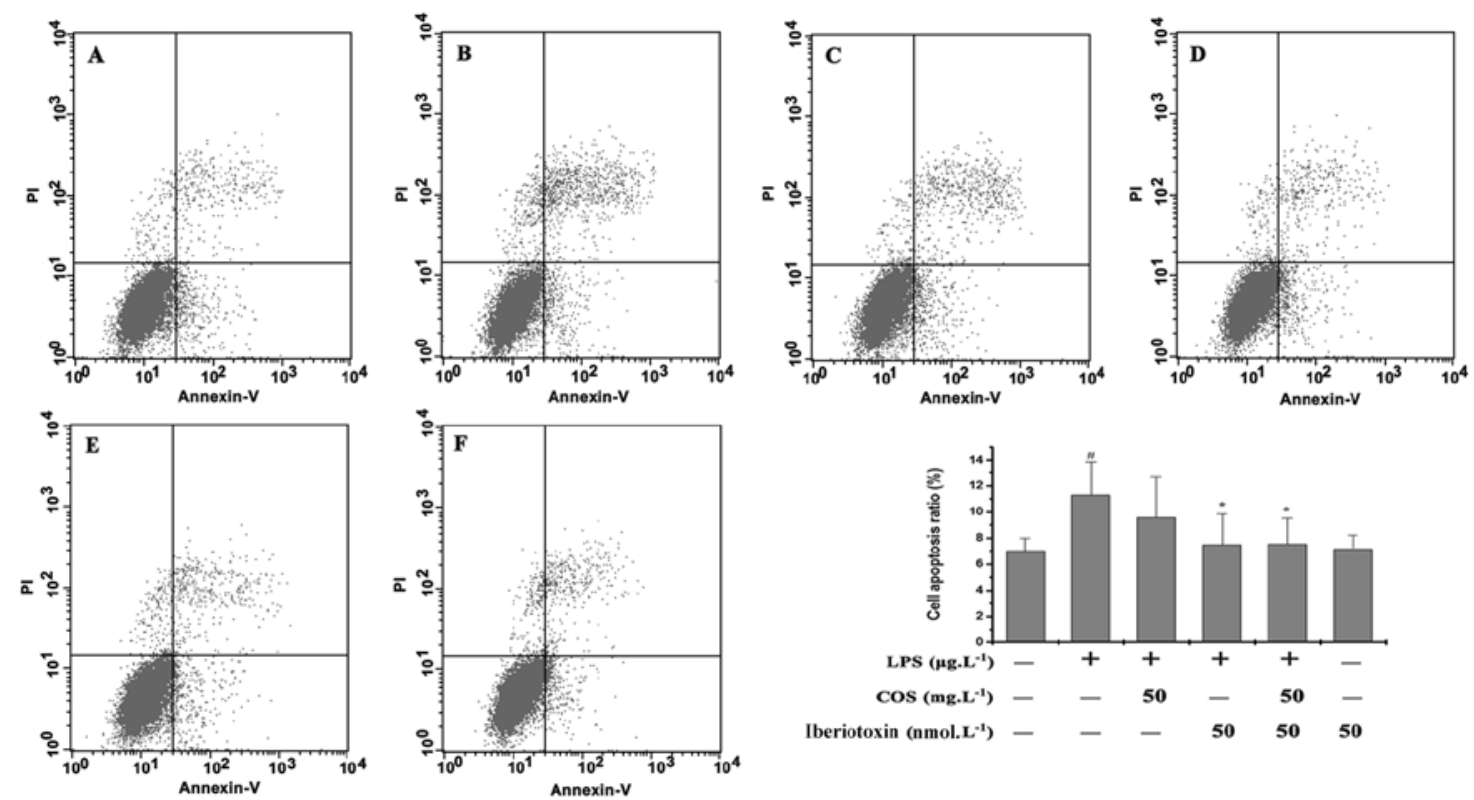

Figure 5. Effects of iberiotoxin (a BKCa channel inhibitor) on the LPS-induced injury of HUVECs. (A) Control group, (B) LPS-treated group, (C) COS $(50 \mathrm{mg} / \mathrm{l})+\operatorname{LPS}(500 \mu \mathrm{g} / \mathrm{l}),(\mathrm{D})$ iberiotoxin $(50 \mathrm{nmol} / \mathrm{l})+\mathrm{LPS}(500 \mu \mathrm{g} / \mathrm{l}),(\mathrm{E})$ iberiotoxin $(50 \mathrm{nmol} / \mathrm{l})+\mathrm{COS}(50 \mathrm{mg} / \mathrm{l})+\mathrm{LPS}(500 \mu \mathrm{g} / \mathrm{l}),(\mathrm{F}) \mathrm{iberiotoxin}$ $(50 \mathrm{nmol} / 1)$. ${ }^{\#} \mathrm{P}<0.05$ vs. the vehicle-treated group; ${ }^{\mathrm{P}}<0.05$ vs. the LPS-treated group.

with $\operatorname{COS}(50 \mathrm{mg} / \mathrm{l})$ for $24 \mathrm{~h}$ and induced by LPS for $4 \mathrm{~h}$, the BKCa channel opening was to some extent inhibited $(\mathrm{P}<0.05)$. Overall the results support the notion that COS can protect endothelial cells through regulating the opening of the $\mathrm{BKCa}$ channel.

The BKCa channel inhibitor prevents LPS-induced cell apoptosis. In order to further investigate whether the opening of the $\mathrm{BKCa}$ channel is associated with the protective effect of COS on preventing LPS-induced injury of HUVECs, cells were treated by a specific BKCa channel inhibitor (iberiotoxin) to detect its effect on cell apoptosis. After pretreatment with COS for $24 \mathrm{~h}(50 \mathrm{mg} / \mathrm{l})$ and treatment with LPS for $4 \mathrm{~h}$ cells were stimulated by iberiotoxin $(50 \mathrm{nmol} / \mathrm{l})$ for $10 \mathrm{~min}$. The results show that the apoptosis ratio of HUVECs was $11.3 \%(\mathrm{P}<0.05)$ after treatment with LPS alone for $4 \mathrm{~h}$, and that its apoptosis ratio was $7.5 \%$ after stimulation by iberiotoxin $(50 \mathrm{nmol} / \mathrm{l})$ for $10 \mathrm{~min}$ and treatment with LPS for $4 \mathrm{~h}$. However, after pretreatment with COS for $24 \mathrm{~h}$, stimulation by iberiotoxin for $10 \mathrm{~min}$ and treatment by LPS for $4 \mathrm{~h}$, the apoptosis ratio was $7.0 \%(\mathrm{P}<0.05)$ (Fig. 5). The specific BKCa channel blocker iberiotoxin is similar to COS in that it can inhibit the cell apoptosis induced by LPS, proving that the BKCa channel opening is likely related to the inhibitory effect of COS on preventing LPS-induced cell apoptosis.

Expression of genes related to the COS inhibition of $L P S$-induced cell apoptosis. In order to discuss the related pathways through which COS inhibits LPS-induced cell apoptosis, RT-PCR and western blot analysis were performed to analyze Bcl-2, Bax and caspase-3 expression. The results show that the Bax mRNA (Fig. 6A) and protein expression levels (Fig. 6B), significantly increased compared with the control group $(\mathrm{P}<0.05)$ after the cells were induced by LPS for 4 or $8 \mathrm{~h}$, while the expression of Bcl-2 was obviously inhibited. Furthermore, the expression level of the downstream cell apoptosis-related protein caspase-3 increased (Fig. 6C). After pretreatment with COS (50 or $200 \mathrm{mg} / \mathrm{l}$ ) or the positive control drug VitC $(100 \mathrm{mg} / \mathrm{l})$ for $24 \mathrm{~h}$, the increase in the mRNA and protein expression levels of Bax induced by LPS was clearly inhibited. As similar effect was observed for the protein expression of caspase-3. The LPS-induced decrease in the mRNA and protein expression levels of Bcl-2 were reversed by COS (Fig. 6D). As indicated by the above results, one pathway through which COS inhibits LPS-induced cell apoptosis may be the alteration of intracellular $\mathrm{Ca}^{2+}$ concentration as result of the its regulation of BKCa channel function, therefore causing a change of the Bcl-2/ Bax ratio on the mitochondrial membrane. A series of cascade actions resulted alterations of the activity of the apoptosisrelated protein caspase-3, suggesting that COS plays a protective and inhibitory role in preventing cell apoptosis.

COS inhibition of LPS-induced apoptosis via activation of the p38/MAPK signaling pathway in HUVECs. Protein levels of total and phosphorylated p38 were detected for the purpose of verifying that inhibition of LPS-induced apoptosis in HUVECs by COS is directly linked with the MAPK signaling pathway. After the cells were induced by LPS, western blot analysis was performed to analyze the total and phosphorylated levels of p38. Phosphorylated p38, compared with the control group, significantly increased after the cells were induced by LPS for 30 min (Fig. 7). However, after pretreatment with COS (50 or $200 \mathrm{mg} / \mathrm{l})$ or with the positive control drug VitC (100 mg/l) for $24 \mathrm{~h}$, and induction by LPS for $30 \mathrm{~min}$, the increase in phosphorylated p38 levels was inhibited, indicating that COS plays a protective role in cells possibly through regulating the p38/MAPK signaling pathway.

COS inhibits the LPS-induced decrease in the expression of O-GlcNAc transferase in HUVECs. Due to the common 
$\mathbf{A}$
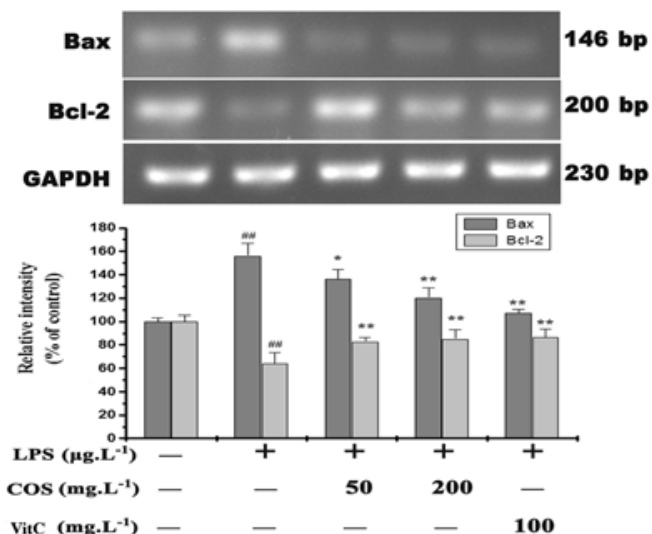

C
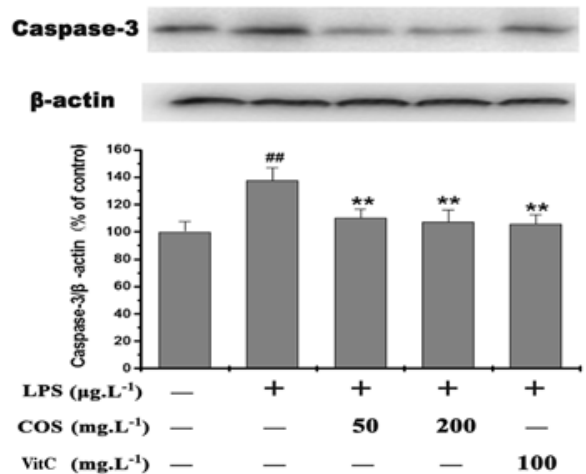

B

Bax

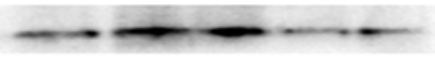

21 kDa

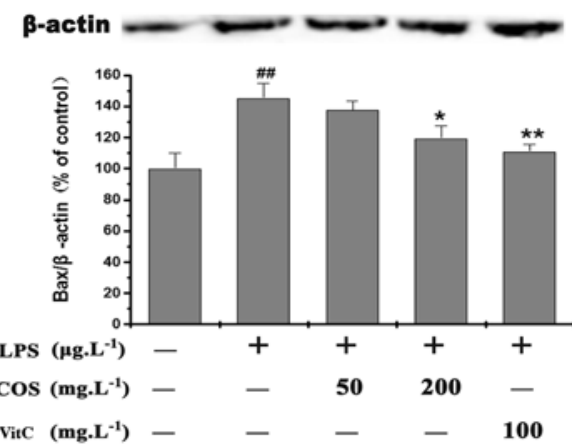

D
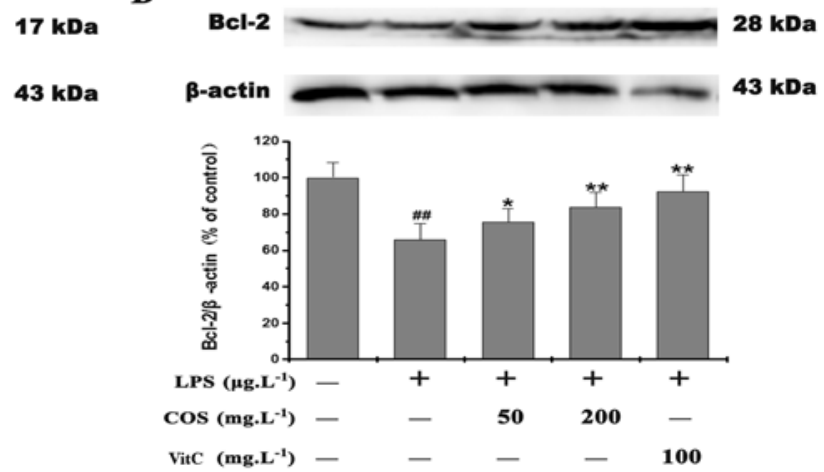

Figure 6. Effects of COS on the LPS-induced expression of (A) Bcl-2 and Bax mRNA, (B) Bax, (C) caspase-3, (D) Bcl-2 protein. ${ }^{\# \#} \mathrm{P}<0.01$ vs. the vehicle-treated group; ${ }^{*} \mathrm{P}<0.05$ vs. the LPS-treated group; ${ }^{* *} \mathrm{P}<0.01$ vs. the LPS-treated group.

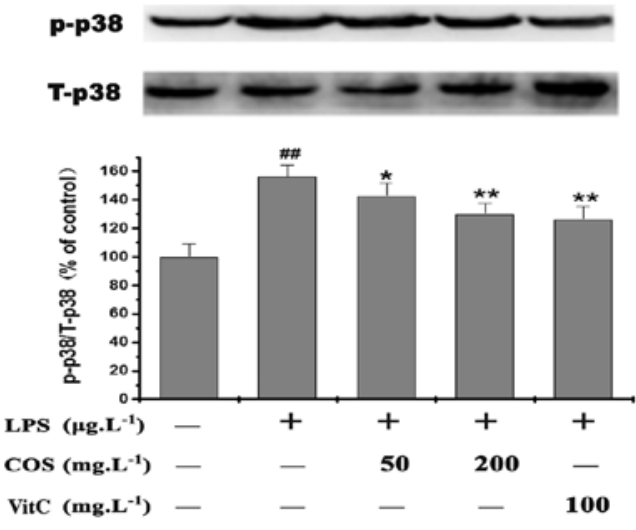

Figure 7. Effects of COS on LPS-induced phosphorylation of p38/MAPK on HUVECs. ${ }^{\# \#} \mathrm{P}<0.01$ vs. the vehicle-treated group; ${ }^{*} \mathrm{P}<0.05$ vs. the LPS-treated group; ${ }^{* *} \mathrm{P}<0.01$ vs. the LPS-treated group.

modification site for the O-GlcNAc-glycosylation and O-phosphorylation of protein, the competition between glycosylation and phosphorylation plays a role in regulating the function of $\mathrm{p} 38$. In order to study whether OGT is involved in the regulation of intracellular phosphorylation of $\mathrm{p} 38$ by COS, western blot analysis was performed to detect the expression of OGT protein. The results show that the expression of OGT protein, compared with the control group, obviously decreased after treatment with LPS for $30 \mathrm{~min}$, which corresponds with the increases in the phosphorylation levels of p38. After pretreatment with COS $(50$ or $200 \mathrm{mg} / \mathrm{l})$ or with the positive control drug VitC (100 mg/l) for $24 \mathrm{~h}$, the decrease in OGT
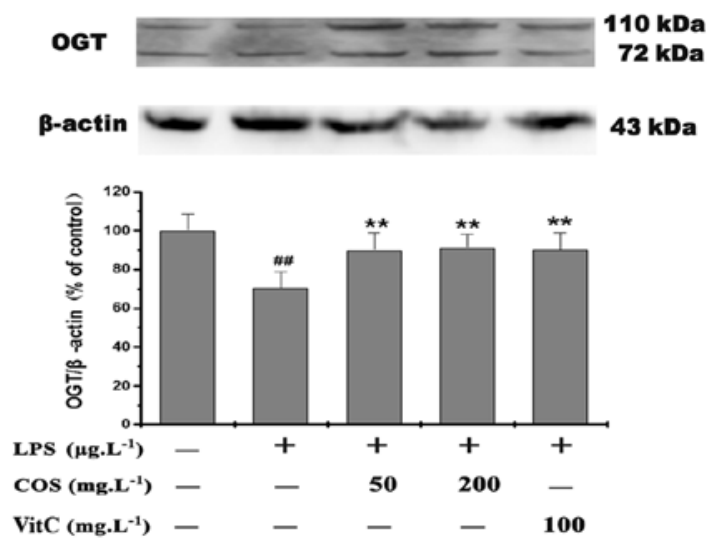

Figure 8. Effects of COS on LPS-induced O-GlcNAc transferase (OGT) ${ }^{\# \#} \mathrm{P}<0.01$ vs. the vehicle-treated group; ${ }^{*} \mathrm{P}<0.05$ vs. the LPS-treated group.

expression in HUVECs, induced by treatment with LPS for $30 \mathrm{~min}$, was clearly inhibited (Fig. 8). Collectively the above results show that the regulation of $\mathrm{p} 38$ by COS may be bi-directional and that O-GlcNAc glycosylation transferase has participated in regulating p38 phosphorylation.

\section{Discussion}

Vascular endothelial cell dysfunction is one of the initiating steps in the formation of atherosclerosis. Vascular endothelial cells are key targets for LPS and various inflammatory cytokines, as well as effector cells (13). Therefore, it is of 


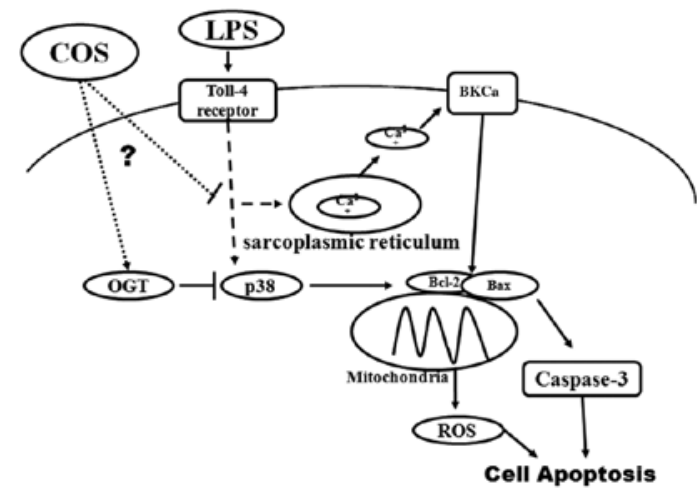

Figure 9. Possible mechanisms of lipopolysaccharide (LPS)-induced apoptosis in human umbilical vein endothelial cells and the effects of chitosan oligosaccharides (COS) in this process.

great significance to discover how to reduce the LPS-induced endothelial injury. This study provides evidence that COS is capable of preventing the LPS-induced increase of $\mathrm{Ca}^{2+}$ concentration in HUVECs, reducing ROS release and alleviating the LPS-induced endothelial injury by regulating the BKCa channel, so as to lower the cell apoptosis ratio.

The factors and approaches used by LPS to accelerate cell apoptosis have not been clearly clarified. An overview of potential pathways is presented in Fig. 9. Some studies have proven that most approaches of cell apoptosis are closely associated with the intracellular $\mathrm{Ca}^{2+}$ overload (14). In addition, activation of the Toll-4 receptor by LPS may result in sarcoplasmic reticulum $\mathrm{Ca}^{2+}$ release. The intracellular $\mathrm{Ca}^{2+}$ overload results in dysfunction of the mitochondria and of the sarcoplasmic reticulum, thus inducing the occurrence of cell apoptosis (15). On the other hand, $\mathrm{Ca}^{2+}$ accumulation in the cytoplasm may have an effect on the ion channels on the cell membranes, particularly in regulating the opening and closing of $\mathrm{Ca}^{2+}$-dependent channels. The BKCa channel, as a $\mathrm{Ca}^{2+}$ dependent potassium channel is sensitive to inflammatory cytokines. It has been reported that the BKCa channel may be activated by the stimulation of inflammatory cytokines, and alcohol, and that this activation may cause cell apoptosis (14). Furthermore, it has been shown that the chemical compound NS-1619 may accelerate the $\mathrm{Ca}^{2+}$ release from the vascular smooth muscle cell calcium store and result in the increase of $\mathrm{Ca}^{2+}$ concentration in cytoplasm (16). Thus, on the one hand, the BKCa channel is activated; and on the other hand, the mitochondrial membrane is depolarized, both of which initiate the procedure of cell apoptosis $(16,17)$. However, the ion channel inhibitor iberiotoxin reverses these effects. Furthermore, in HEK293 cells which lack the BKCa channel, cell apoptosis was induced regardless of NS-1619 or iberiotoxin (14). This data provide support for the notion that $\mathrm{BKCa}$ is closely related to cell apoptosis.

The present study demonstrated that LPS can accelerate endothelial $\mathrm{Ca}^{2+}$ release, and at the same time increase ROS release, decrease the $\mathrm{Bcl}-2 / \mathrm{Bax}$ ratio and increase caspase-3, all which shows that LPS certainly triggers cell apoptosis through the mitochondrial pathway. In order to prove that this approach is related to the activation of the BKCa channel, the patch clamp technique was applied and the results demonstrated that LPS can activate the BKCa channel. After treatment with the
BKCa-specific inhibitor iberiotoxin, LPS-induced cell apoptosis was inhibited, showing that the BKCa channel is involved in the LPS-induced cell apoptosis in HUVECs. However, COS was able to inhibit the endothelial $\mathrm{Ca}^{2+}$ release, the increase of ROS release, the drop of the $\mathrm{Bcl}-2 / \mathrm{Bax}$ ratio and the increase of caspase-3 induced by LPS, as well as the activation of the $\mathrm{BKCa}$ channel. Collectively, the results show that one of the action mechanisms of COS inhibition of cell apoptosis is its participation in the regulation of the BKCa channel.

Further studies are needed to verify whether cell apoptosis is further accelerates by the transmission of relating signaling pathway after activation of the $\mathrm{BKCa}$ ion channel. This experiment has investigated the p38/MAPK signaling pathway related to cell apoptosis. The study showed that the activation of the p38/MAPK signaling pathway may alter the ratio of the anti-apoptotic protein Bcl-2 and the pro-apoptotic protein Bax, and even process caspase-9 or caspase-11 into active caspase-3, and thus apoptosis is started (18). We have found that LPS can accelerate p38 phosphorylation while COS can inhibit p38 phosphorylation. However, whether this process is related to the activation of the $\mathrm{BKCa}$ channel remains unknown.

The results of previous studies show that COS may regulate $\mathrm{p} 38$ /MAPK signaling through regulating the interaction of p38 protein phosphorylation or glycosylation so as to affect the expression of IL- 6 and IL- 8 induced by TNF- $\alpha(4,19)$. The p38 protein can be immediately $\mathrm{O}$-glycosylated and also phosphorylated at a serine/threonine site, and the interaction of O-glycosylation and phosphorylation plays a central role in regulating p38 activity. OGT is a key enzyme to catalyze $\mathrm{O}$-glycosylation in the functional protein. We have found that treatment with LPS accelerated p38 phosphorylation and decreased OGT expression. However, COS reversed this phenomenon, that is COS increased OGT expression so as to enhance the p38 target protein glycosylation. This resulted in reduction of phosphorylation to some extent. Collectively this study demonstrates that there may be a phenomenon that COS inhibits cell apoptosis through the regulation of various processes.

\section{Acknowledgements}

We are grateful for the financial support from the National Nature Science Foundation of China (project no. 81070222), the Nature Science Foundation of Chongqing (project no. CSTC, 2009BA5083) and the Key Foundation of Chongqing Medical University (project no. XBED 200806).

\section{References}

1. Ross R: Atherosclerosis - an inflammatory disease. N Engl J Med 340: 115-126, 1999.

2. Liu HT, Li WM, Li XY, et al: Chitosan oligosaccharides inhibit the expression of interleukin- 6 in lipopolysaccharide-induced human umbilical vein endothelial cells through $\mathrm{p} 38$ and ERK1/2 protein kinases. Basic Clin Pharmacol Toxicol 106: 362-371, 2009.

3. Liu HT, He JL, Li WM, et al: Geniposide inhibits interleukin-6 and interleukin- 8 production in lipopolysaccharide-induced human umbilical vein endothelial cells by blocking p38 and ERK1/2 signaling pathways. Inflamm Res 59: 451-461, 2010.

4. Yang TN, Jilang YQ, Yu C, et al: Chitosan oligosaccharides suppress interleukin- 6 and interleukin-8 production in vascular endothelial cells EA.hy926 induced by TNF- $\alpha$ via increasing p38MAPK protein O-GlcNAc modification. Chin Pharmacol Bull 27: 252-257, 2011. 
5. Xu Y, Zhang Q, Yu S, Yang Y, et al: The protective effects of chitooligosaccharides against glucose deprivation-induced cell apoptosis in cultured cortical neurons through activation of PI3K/ Akt and MEK/ERK1/2 pathways. Brain Res 1375: 49-58, 2011.

6. Park JK, Chung MJ, Choi HN, et al: Effects of the molecular weight and the degree of deacetylation of chitosan oligosaccharides on antitumor activity. Int J Mol Sci 12: 266-277, 2011.

7. Liu HT, Li WM, Xu G, et al: Chitosan oligosaccharides attenuate hydrogen peroxide-induced stress injury in human umbilical vein endothelial cells. Pharmacol Res 59: 167-175, 2009.

8. Liu HT, Li WM, Xu G, et al: Chitosan oligosaccharides protect human umbilical vein endothelial cells from hydrogen peroxideinduced apoptosis. Carbohydrate Polymers 80: 1062-1071, 2010.

9. Ye CL, Shen B, Ren XD, et al: An increase in opening of BKCa channels in smooth muscle cells in streptozotocin-induced diabetic mice. Acta Pharmacol Sin 25: 744-750, 2004.

10. Zhang HF, Chen XQ, Hu GY, et al: Magnesium lithospermate B dilates mesenteric arteries by activating $\mathrm{BKCa}$ currents and contracts arteries by inhibiting K(V) currents. Acta Pharmacol Sin 31: 665-670, 2010

11. Ross FA, Rafferty JN, Dallas ML, et al: Selective expression in carotid body type I cells of a single splice variant of the large conductance calcium- and voltage-activated potassium channel confers regulation by AMP-activated protein kinase. J Biol Chem 286: 11929-11936, 2011.

12. Krick S, Platoshyn O, Sweeney M, et al: Nitric oxide induces apoptosis by activating $\mathrm{K}^{+}$channels in pulmonary vascular smooth muscle cells. Am J Physiol Heart Circ Physiol 282: H184-H193, 2002.
13. Schulz B, Pruessmeyer J, Maretzky T, et al: ADAM10 regulates endothelial permeability and T-cell transmigration by proteolysis of vascular endothelial cadherin. Circ Res 102: 1192-1201, 2008.

14. Xie MJ, Ma YG, Gao F, Bai YG, Cheng JH, Chang YM, Yu ZB and Ma J: Activation of BKCa channel is associated with increased apoptosis of cerebrovascular smooth muscle cells in simulated microgravity rats. Am J Physiol Cell Physiol 298: C1489-C1500, 2010.

15. Huang P, Yu C, Liu XQ, et al: Cytotoxicity of tubeimoside I in human choriocarcinoma JEG-3 cells by induction of cytochrome $\mathrm{c}$ release and apoptosis via the mitochondrial-related signaling pathway. Int J Mol Med 28: 579-587, 2011.

16. Korper S, Nolte F, Rojewski MT, Thiel E and Schrezenmeier H: The $\mathrm{K}^{+}$channel openers diazoxide and NS1619 induce depolarization of mitochondria and have differential effects on cell $\mathrm{Ca}^{2+}$ in CD34 ${ }^{+}$cell line KG-1a. Exp Hematol 31: 815-823, 2003.

17. Han X, Xi L, Wang H, Huang X, Ma X, Han Z, Wu P, Ma X, Lu Y, Wang G, Zhou J and Ma D: The potassium ion channel opener NS1619 inhibits proliferation and induces apoptosis in A2780 ovarian cancer cells. Biochem Biophys Res Commun 375: 205-209, 2008.

18. Kuwana T and Newmeyer DD: Bcl-2-family proteins and the role of mitochondria in apoptosis. Curr Opin Cell Biol 15: 691-699, 2003.

19. Luo B, Soesanto Y, McClain DA, et al: Protein modification by O-linked GlcNAc reduces angiogenesis by inhibiting Akt activity in endothelial cells. Arterioscler Thromb Vasc Biol 28: 651-657, 2008 